\section{Extrafoveal vitreous traction associated with diabetic diffuse macular oedema}

\begin{abstract}
Purpose To present an association between diabetic diffuse macular oedema and extrafoveal vitreous traction by optical

Keywords: diabetic macular oedema; diffuse macular oedema; extrafoveal vitreous traction; vitreopapillary traction; vitreofoveal traction; optical coherence tomography
\end{abstract} coherence tomography (OCT).

Methods In a retrospective study, charts and OCT scans of diabetic patients with macular oedema were reviewed. Eyes with either vitreofoveal or extrafoveal traction were included. Eyes that had vitreoretinal adherence with no sign of traction, idiopathic vitreomacular traction syndrome, or vitreoretinal surgery were excluded. Macular maps were compared with normal controls $(n=12)$.

Results Of the 186 eyes of 122 consecutive patients, 45 eyes (41 patients) were analyzed. Vitreofoveal traction was detected in 25 eyes $(56 \%)$ and extrafoveal traction in $20(44 \%)$, either at the retina $(16 ; 35 \%)$ or at the optic nerve head $(4 ; 9 \%)$. Of these 20 eyes, related extrafoveal retinal oedema was in continuum with the central macular oedema, manifesting as diffuse macular oedema, in 16 (36\% of all 45$)$ eyes. Vitreous adherence was detected by the centrally fixated Automatic 6-radial lines program in 26 eyes (58\%): 5 (25\%) of 20 with extrafoveal traction and $21(84 \%)$ of 25 with vitreofoveal traction. In the other $19(42 \%)$ eyes, the vitreous traction site was detected only by the Line group OCT-2000 program, which is manually controllable during the scanning process.

Conclusions Diabetic diffuse macular oedema may be related to an extrafoveal vitreous traction. The traction sites were detected in a large proportion of eyes only by the OCT Line group program and not by the Automatic 6-radial lines program. Further studies are required to validate the clinical consequence of these findings.

Eye (2010) 24, 347-353; doi:10.1038/eye.2009.106; published online 15 May 2009
A Ophir ${ }^{1,2}$, A Trevino $^{1}$ and S Fatum ${ }^{1}$

\section{Introduction}

Macular oedema secondary to diabetic retinopathy is often related to the breakdown of the inner blood-retina barrier and/or to an ischaemic insult. ${ }^{1-5}$ Beneficial effects were found after focal laser photocoagulation for the treatment of clinically significant diabetic macular oedema (DME), ${ }^{6}$ whereas grid laser treatment has limited results in eyes with diffuse DME. ${ }^{7}$ Recent reports show that a temporary improvement of diffuse DME may be achieved by intravitreal or sub-Tenon's administration of triamcinolone acetonide $\mathrm{e}^{8-10}$ and/or intravitreal injection of vascular endothelial growth-factor inhibitor. ${ }^{11,12}$

Other factors, especially vitreofoveal traction, may result in macular oedema and affect its evolution. ${ }^{13-15}$ In eyes with non-proliferative or proliferative diabetic retinopathy, it has been reported, using optical coherence tomography (OCT), that a vitreous traction at the optic nerve head $(\mathrm{ONH})$ may result in diffuse oedema and/ or serous retinal detachment located between the $\mathrm{ONH}$ and the macula. ${ }^{16}$

Pars plana vitrectomy (PPV) was found commonly beneficial in eyes with diffuse DME associated with vitreomacular traction. ${ }^{17-19}$ The surgical outcome was variable in different studies if no vitreomacular traction was apparent. ${ }^{14,20}$ In such eyes, La Heij et al ${ }^{21}$ found that surgical success was significantly better in eyes that had not had previous laser treatment(s) than in eyes that had undergone laser photocoagulation for DME. The authors partly related the reduced benefit of PPV in 'non-tractional' macular oedema in some of the
${ }^{1}$ Division of Ophthalmology, Hillel-Yaffe Medical Center, Hadera, Israel

${ }^{2}$ The Ruth and Bruce Rappaport Faculty of Medicine, The Technion, Haifa, Israel

Correspondence: A Ophir, Division of Ophthalmology, Hillel-Yaffe Medical Centre, P.O.Box 169, Hadera, Israel 38100, Israel. Tel.: 9725472226888 ; Fax: 97235409222. E-mail: ophthalmology@ hy.health.gov.il

Received: 8 December 2008 Accepted in revised form: 14 April 2009 Published online: 15 May 2009

Proprietary interest: None 
previous studies to repeated laser applications and to greater endurance of the oedema before PPV took place. In none of the aforementioned studies on surgical outcome for DME was extrafoveal vitreous traction reported or ruled out.

To examine various macular abnormalities, such as macular oedema, the central Automatic 6-radial lines program of OCT-2000 (OCT-2) or the automatic Fast macular map program in Stratus OCT (OCT-3) is commonly used. $\mathrm{Hee}^{22}$ notes that poor scan acquisition, for example, maladjustment of the OCT focus, might result in a 'degraded image' and in artifacts. In this study, we present OCT-2 findings in consecutive patients with DME, in which vitreous traction was detected at the central macula or at other sites at the posterior pole. Extrafoveal traction sites are illustrated to be commonly associated with diffuse macular oedema. As far as we are aware (search through Entrez Pubmed), except for vitreopapillary traction associated with diffuse macular oedema, ${ }^{16}$ this was not previously reported.

\section{Materials and methods}

In a retrospective study, we reviewed the charts of consecutive patients of our OCT series, who had DME in the presence of either vitreofoveal or extrafoveal vitreous traction. As anatomical boundaries of the elevated oedematous macula cannot usually be precisely delineated, we designated vitreous traction at the central macula as 'vitreofoveal traction'. Vitreous traction away from the central elevated macula, either at the retina or at the $\mathrm{ONH}$, was designated as 'extrafoveal traction'. Evidence of traction required the presence of vitreous adherence to the retina or to the $\mathrm{ONH}$, associated with tissue elevation and deformity at the traction site. Exclusion criteria were eyes with idiopathic vitreomacular traction syndrome, eyes that had undergone vitreoretinal surgery, eyes with vitreoretinal adherence but without signs of traction, and eyes in which scans were not of a high enough quality for a proper diagnosis. On the basis of our normative data, as well as on other studies, fovea was considered oedematous when its thickness was $>200 \mu .^{23-25}$ The 6-mm OCT macular maps were compared with agematched normal controls $(n=12)$. Research was adhered to the tenets of the Declaration of Helsinki Institutional Ethics Committee approval was obtained.

After the clinical examination, the Automatic 6-radial lines program of the OCT (Humphrey Zeiss Inc., San Leandro, CA, USA) was directed towards the fixation point and was focused on the macula. (In this OCT-2, the six radial lines centred on the fovea are obtained individually, oriented $30^{\circ}$ from one another, whereas the OCT-3 fast macular map program provides six scans rapidly obtained in a radial spoke pattern). This is routinely followed by the determination of the scan length and angle and site of examination using the Line group program, which the examiner controls manually by focus. If reflectivity of a vitreous strand or the posterior hyaloid, though without vitreous adherence, is detected in any of the six radial scans, a search by the Line group program is then initiated to the site where it is seen, at various angles and at various lengths (a shorter scan increases resolution), with frequent focus changes during the scanning process, to search for the vitreous traction point. The examination is completed using the Line group program throughout the field detected by the OCT video. The examination is usually discontinued upon detection of a vitreous traction site.

The OCT results were related to four subgroups, depending on the location of the vitreous traction: (I) 'vitreofoveal', at the central macula and (II) 'extrafoveal', which included either the, (a) papillomacular bundle (PMB) site, (b) the posterior pole elsewhere, that is, the vitreoretinal traction between the vascular arcades but away from the $\mathrm{PMB}$, or (c) the $\mathrm{ONH}$, that is, vitreopapillary traction (Table 1). These subgroups were compared with regard to prevalence, whether the associated retinal oedema or subretinal fluid was in continuum with the macula, and the OCT program in which vitreous traction was confirmed. Statistical analysis between the vitreofoveal traction subgroup and the other three subgroups in relation to BCVA (calculations were made by Log-MAR) and foveal thickness was carried out using Student's $t$-test.

\section{Results}

A total of 186 eyes of 122 consecutive patients were examined between July 2004 and May 2008, and were found in our OCT diagnostic list to have proliferative or non-proliferative DME. Of them, 45 eyes (24\%) of 41 patients were confirmed by OCT to be associated with vitreofoveal or extrafoveal vitreous traction (Table 1). One eye with vitreoretinal attachment without signs of traction was excluded.

Extrafoveal vitreous traction was apparent in 20 of the 45 eyes (44\%) eyes presented in the three aforementioned subgroups (Table 1). In some eyes, there seemed to be a localized serous retinal detachment or schisis-like cleft at the point of the vitreous traction, in addition to the retinal oedema at that site (Figures 1 and 2). In each, the fluid at the traction site seemed to integrate with the adjoining diffuse oedema. Of the subgroups in which vitreous traction was detected, that is, at the PMB axis $(n=9$; Figure 1), at the 'posterior pole elsewhere' $(n=7$; Figure 2), and at the $\mathrm{ONH}(n=4$; Figure 3$)$, the adjoining 
Table 1 Characteristics of 45 eyes of 41 patients with vitreous traction and diabetic macular oedema

\begin{tabular}{|c|c|c|c|c|c|}
\hline & $\begin{array}{c}\text { Vitreo-foveal } \\
\text { traction eyes (\%) }\end{array}$ & $\begin{array}{c}\text { Vitreo-PMB } \\
\text { traction eyes (\%) }\end{array}$ & $\begin{array}{l}\text { Posterior pole retinal } \\
\text { traction elsewhere eyes (\%) }\end{array}$ & $\begin{array}{l}\text { Vitreopapillary } \\
\text { traction eyes (\%) }\end{array}$ & $\begin{array}{c}\text { Total } \\
\text { eyes (\%) }\end{array}$ \\
\hline \multicolumn{6}{|c|}{ (A) Location of vitreous traction $(\mathrm{n}=45)$} \\
\hline No. of eyes & $25(56)$ & $9(20)$ & $7(15)$ & $4(9)$ & 45 \\
\hline BCVA, range (LogMAR) & $0.3-1.3$ & $0.5-1$ & $0.2-1.7$ & $0.3-1$ & \\
\hline Mean \pm SD $\left(P\right.$-value $\left.{ }^{\mathrm{a}}\right)$ & $0.6 \pm 0.3$ & $0.8 \pm 0.1(>0.1)$ & $0.8 \pm 0.6(>0.1)$ & $0.6 \pm 0.4(>0.1)$ & \\
\hline Macular thickness, range $(\mu)$ & $230-590$ & $230-566$ & $235-450$ & 253-301 & \\
\hline Mean \pm SD $\left(P\right.$-value $\left.{ }^{\text {a }}\right)$ & $401 \pm 105$ & $409 \pm 111(>0.1)$ & $306 \pm 70(=0.029)$ & $272 \pm 21(<0.001)$ & \\
\hline Detected with the automated & & & & & \\
\hline 6-Radial lines program & $21(84)$ & $3(33)$ & $2(28)$ & 0 & $26(58)$ \\
\hline $\begin{array}{l}\text { Detected only by line group } \\
\text { program }\end{array}$ & $4(16)$ & $6(67)$ & $5(71)$ & $4(100)$ & $19(42)$ \\
\hline \multicolumn{6}{|c|}{ (B) Oedema at traction site in continuum with the central macular oedema $(\mathrm{n}=41)$} \\
\hline & $25(100)^{\mathrm{b}}$ & $7(78)^{\mathrm{b}}$ & $5(71)^{\mathrm{b}}$ & $4(100)^{\mathrm{b}}$ & $41^{\mathrm{c}}(91)$ \\
\hline
\end{tabular}

$\mathrm{BCVA}$, best-corrected visual acuity; SD, standard deviation; $\mathrm{PMB}$, papillomacular bundle.

Posterior pole retinal traction elsewhere = traction at the retina between the vascular arcades, except for the PMB site.

'Student's $t$-test; comparison between vitreomacular traction subgroup and each of the other three subgroups.

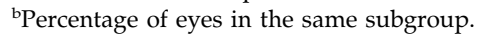

'In four additional eyes no association was verified between the oedema at traction site and macula oedema.
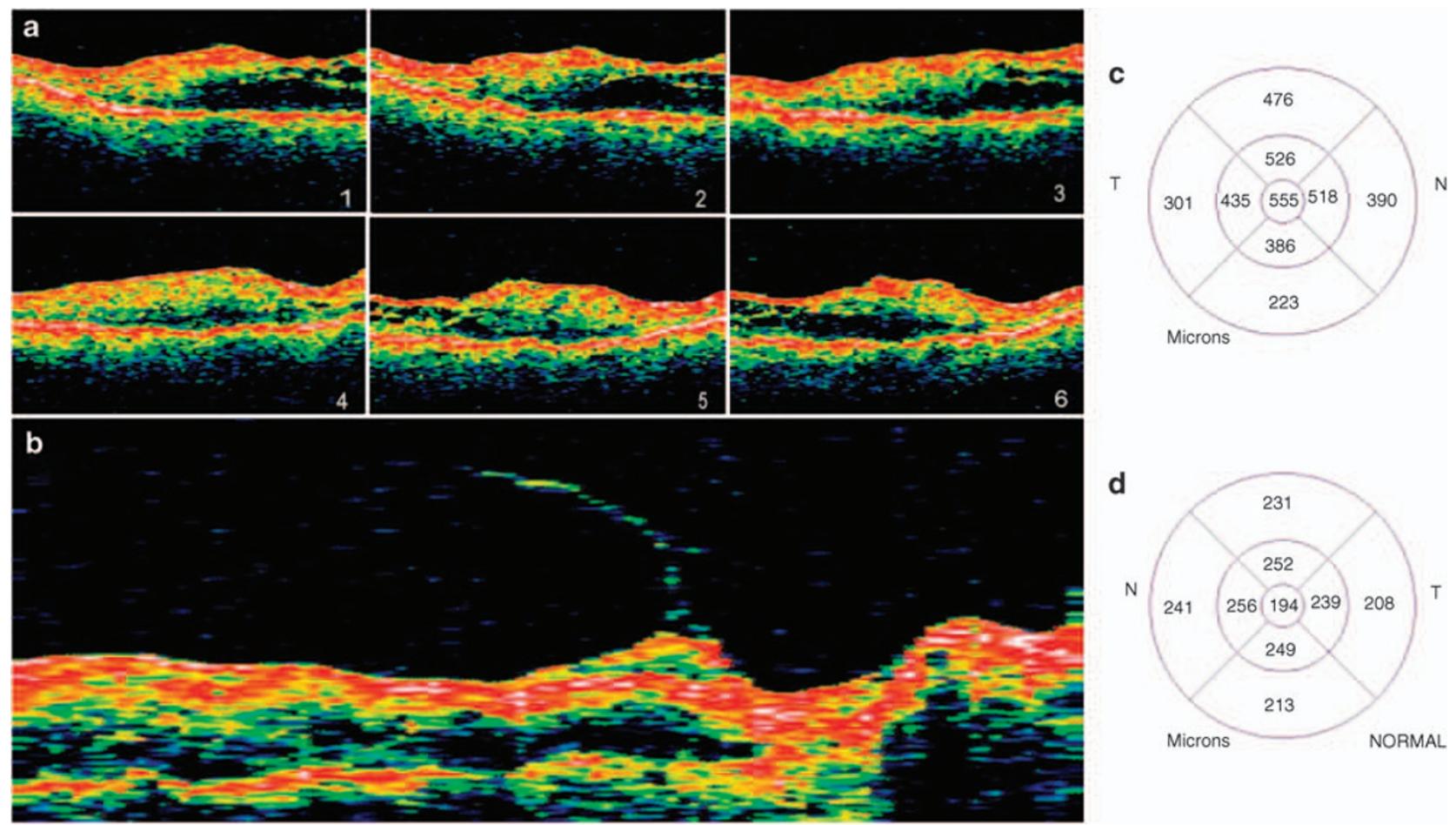

Figure 1 Diffuse diabetic macular oedema and extrafoveal traction in the RE of a 80-year-old patient (case no. 5). (a) Macular oedema is illustrated by the OCT, whereas hyper-reflective vitreous strand is not detected in any of the scans provided by the Automatic 6-radial lines program. (b) Vitreoretinal traction and localized serous retinal detachment at the papillomacular bundle site, close to the optic nerve head (ONH; horizontal scan) is detected by the OCT-2 Line group program. There is a direct association of the retinal oedema underlying the traction site to that at the central macula. The $\mathrm{ONH}$ is also elevated. (c) A 6-mm macular map discloses diffuse thickened macula, 55 to $186 \%$ thicker than that in the normal controls (d), in all four quadrants, except at the outer inferior site. (d) A 6-mm macular map of the age-matched normal controls $(n=12)$.

retinal oedema was in continuum with the macular oedema in 7,5, and 4 eyes, respectively. Altogether, direct continuation of the retinal oedema underlying or adjoining the extrafoveal vitreous traction site and that at the central macula was detected in $80 \%$ (16 of 20) of eyes with extrafoveal traction, or in $36 \%$ of all 45 eyes, each 

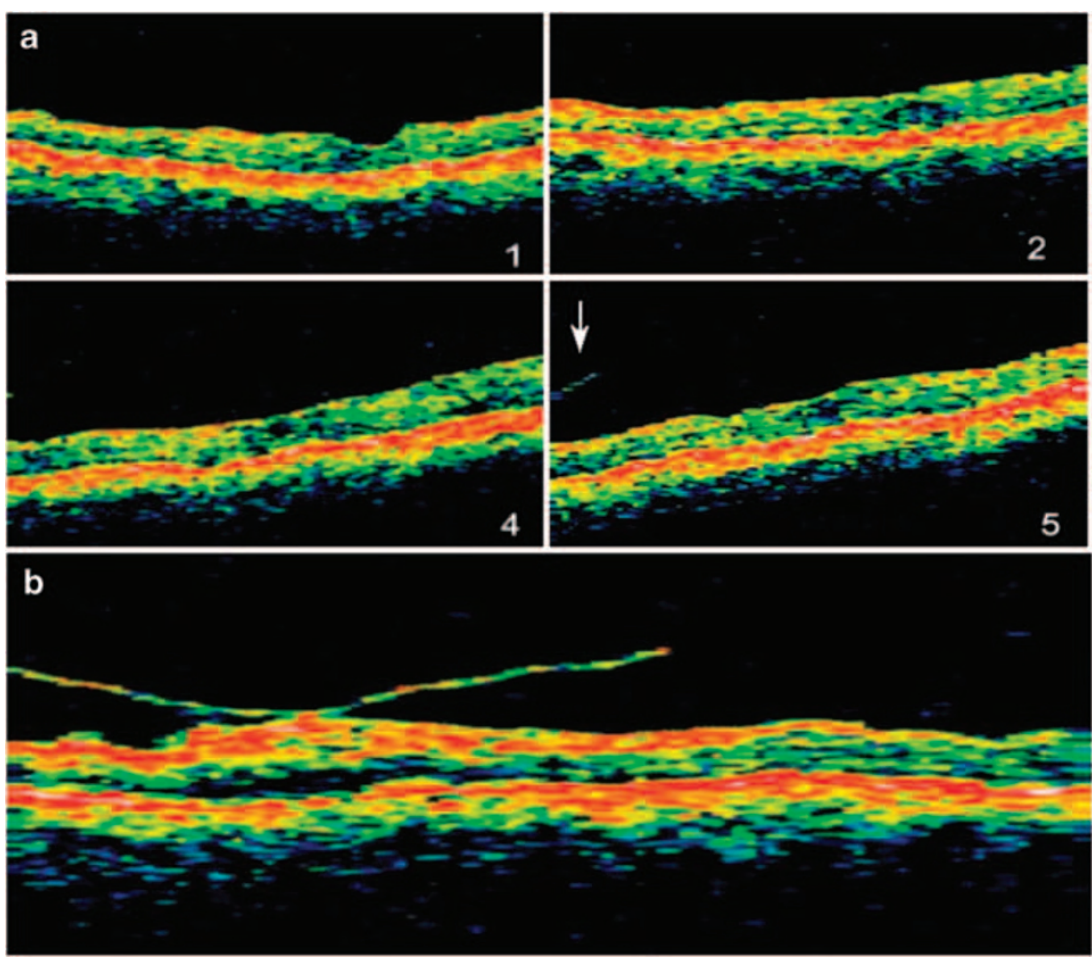
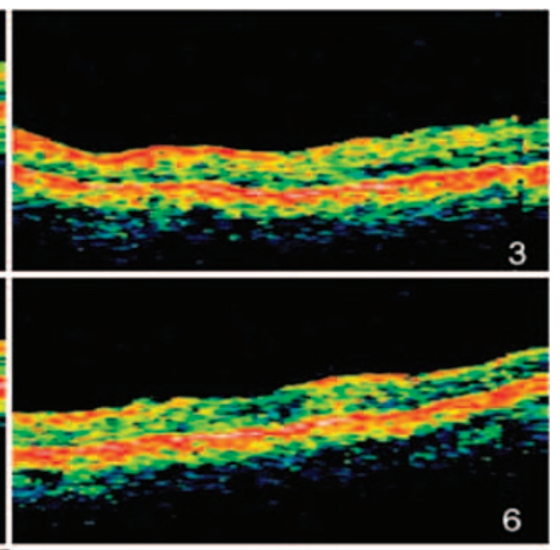

C

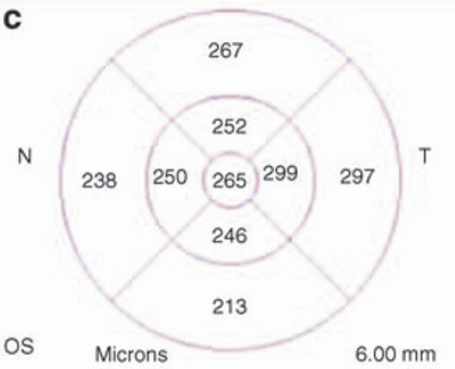

Figure 2 Diffuse diabetic macular oedema and extrafoveal traction in the LE of a 73-year-old patient (case no. 15). (a) Macular oedema is illustrated by the Automatic 6-radial lines program of the OCT. A non-adherent hyper-reflective vitreous strand is detected in scan 5 (arrow). (b) Vitreoretinal traction and localized serous retinal detachment are detected by the Line group program at an extrafoveal site, supero-temporal to the central macula. (c) A 6-mm macular map discloses diffuse thickened temporo-superior quadrants, 43 to $15 \%$ thicker than that in the normal controls, in continuum with the thickened central macula. (Data of normal macular thickness are presented in part d of Figure 1).
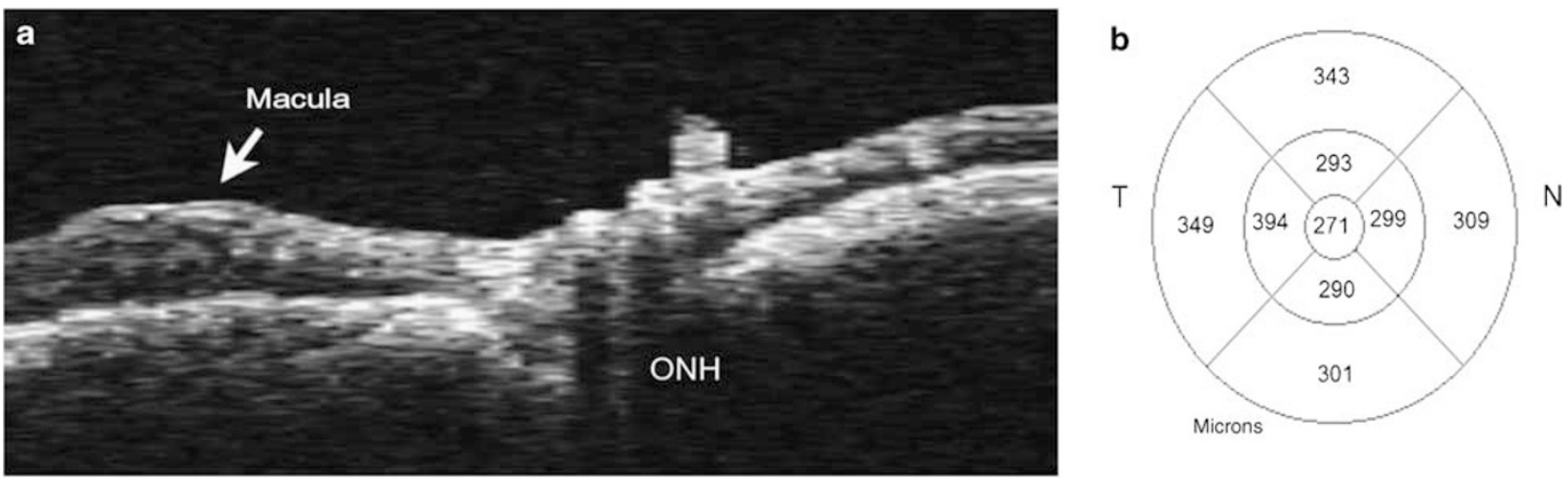

Figure 3 Diffuse diabetic macular oedema and vitreopapillary traction in a 55-year-old patient (case no. 13). (a) The use of the Line group program enabled diagnosing of vitreopapillary traction. Retinal oedema is detected adjacent and temporal to the traction site, in association with the central macular oedema. $\mathrm{ONH}=$ optic nerve head. (b) The 6-mm macular map discloses diffuse thickened macula, 16-68\% thicker than that in the normal controls (see normal data in Figure 1-d) at all nine sites of the four quadrants.

manifesting as diffuse macular oedema (Table 1 and Figures 1-3). The Automatic 6-radial lines program detected extrafoveal vitreo-retinal traction sites in five of the 20 eyes (25\%): in three eyes at the PMB axis and in two at the 'posterior pole elsewhere' (Table 1). The Line group program enabled the detection of extrafoveal traction sites in the other 15 eyes (Tables 1 and 2).
Vitreofoveal traction was detected in the other 25 eyes (56\%; Table 1). With the Automatic 6-radial lines program, diagnosis of vitreofoveal adherence was made in only $21(84 \%)$ of these eyes, whereas it was indecisive in the other four eyes. Thereafter, only the Line group program confirmed vitreofoveal adherence and traction in these four eyes (see Supplementary Figure 4 online), 
Table 2 Nineteen eyes (19 patients) with diabetic macular oedema and vitreoretinal or vitreopapillary traction that were detected only by the Line group program of the OCT-2

\begin{tabular}{|c|c|c|c|c|c|c|c|c|c|}
\hline Eye no. & Gender & $\begin{array}{l}\text { Age } \\
\text { (years) }\end{array}$ & $\begin{array}{c}B C V A \\
\log M A R\end{array}$ & $\begin{array}{c}\text { Foveal } \\
\text { thickness }(\mu)\end{array}$ & VT-fovea & $V T-P M B$ & $V T-P P E$ & VT-ONH & $\begin{array}{l}\text { Traction-associated retinal oedema in } \\
\text { continuum with the central ME }\end{array}$ \\
\hline 1 & M & 60 & 0.8 & 322 & & Yes & & & Yes \\
\hline 2 & M & 58 & 0.8 & 566 & & Yes & & & No \\
\hline 3 & $\mathrm{~F}$ & 75 & 0.48 & 271 & Yes & & & & Yes \\
\hline 4 & M & 51 & 0.48 & 450 & & & Yes & & Yes \\
\hline 5 & M & 80 & 0.8 & 555 & & Yes & & & Yes \\
\hline 6 & M & 69 & 0.8 & 374 & & Yes & & & Yes \\
\hline 7 & M & 64 & 1 & 494 & Yes & & & & Yes \\
\hline 8 & $\mathrm{~F}$ & 69 & 0.18 & 282 & & Yes & $Y_{e s}{ }^{b}$ & & Yes \\
\hline 9 & F & 60 & 0.6 & 440 & Yes & & & & Yes \\
\hline $10 \mathrm{R}^{\mathrm{a}}$ & F & 78 & 1.45 & 269 & & & Yes & & No \\
\hline $11 \mathrm{~L}^{\mathrm{a}}$ & F & 74 & 1 & 460 & & Yes & & & Yes \\
\hline 12 & F & 64 & 0.18 & 248 & Yes $^{\mathrm{b}}$ & Yes & Yes & & Yes \\
\hline 13 & $\mathrm{~F}$ & 55 & 0.6 & 271 & & & & Yes & Yes \\
\hline 14 & M & 72 & 1 & 390 & & Yes & & & No \\
\hline $15 \mathrm{~L}^{\mathrm{a}}$ & M & 73 & 0.8 & 265 & & & Yes & & Yes \\
\hline 16 & $\mathrm{~F}$ & 71 & 0.18 & 235 & & & Yes & & Yes \\
\hline 17 & F & 62 & 0.3 & 301 & & & & Yes & Yes \\
\hline 18 & F & 62 & 0.3 & 264 & & & Yes & $\mathrm{Yes}^{\mathrm{b}}$ & Yes \\
\hline 19 & $\mathrm{~F}$ & 72 & 0.8 & 253 & & & & Yes & Yes \\
\hline Mean & & 66.8 & 0.7 & 353.1 & & & & & \\
\hline $\mathrm{SD} \pm$ & & 8.0 & 0.4 & 109.6 & & & & & \\
\hline
\end{tabular}

BCVA, best-corrected visual acuity; ME, macular oedema; VT, vitreous traction; VT-ONH, vitreous traction at optic nerve head; VT-PMB, vitreous traction at papillomacular bundle; VT-PPE, vitreoretinal traction at the posterior pole elsewhere.

aEach fellow eye had vitreomacular traction and oedema that was detected by the Automatic 6-radial lines program.

'Patients with more than 1 traction site: the site with the sign ' $b$ ' was considered for analysis.

which became possible when the scan focus was manually changed during the scanning process from the central macula to the vitreomacular interface or to the posterior vitreous compartment, thus achieving visible vitreous traction membranes. Diagnosis was also aided by examining within the angles between the $30^{\circ}$ standard sites of the Automatic 6-radial lines program.

Overall, the Automatic 6-radial lines program confirmed vitreoretinal traction at either the central macula or at an extrafoveal site in $26(21 \pm 5 ; 58 \%)$ of the 45 eyes. Of the other 19 eyes, the Automatic 6-radial lines program illustrated 1-4 hyper-reflective fractions per eye of the posterior hyaloid or vitreous strands in $16(84 \%)$ eyes, in $\sim 10-50 \%$ of the scan length (Table 2 , Figure 2 and Supplementary Figure 4). The site of these fractions, each located away from the retina, macula or the $\mathrm{ONH}$, without adherence to these tissues, served as an indicator and landmark of the possible existence of a vitreo-traction membrane. Thereafter, the search by the Line group program was initially directed to their angle of location. Overall, the Line group program confirmed vitreous traction at the central macula in four eyes, which was not verified otherwise (Tables 1 and 2; Supplementary Figure 4), and at an extrafoveal site in 15 eyes (Figures 1-3), which was not detected by the Automatic program. Although the OCT examination was usually discontinued when a traction point was found, in 3 of the 19 eyes (cases nos. 8, 12, and 18, Table 2), multifocal (2 or 3 ) attachment points were detected. In these eyes, the associated retinal oedema found in continuum with the macular oedema was the point of vitreous traction chosen for analysis.

The macular thickness in eyes with vitreofoveal traction was statistically significantly thicker than that in the eyes with vitreoretinal traction at the 'posterior pole elsewhere' or those with vitreopapillary traction (Table 1).

\section{Discussion}

This study revealed that in eyes with DME associated with documented vitreous traction $(n=45)$, the prevalence of extrafoveal vitreous traction $(n=20 ; 44 \%)$ was a relatively common phenomenon. In eyes with extrafoveal traction, the related retinal oedema presented as diffuse macular oedema and was in continuum with the central macular oedema in $80 \%(n=16$ of 20$)$ of the eyes, or in $36 \%$ of all 45 eyes.

In a search for vitreoretinal adherence and traction, where the Automatic 6-radial lines scans crossed a vitreous membrane or the posterior hyaloid without detecting vitreoretinal adherence, often (16 of 19 eyes, 
$84 \%$ ) a part of it was detected. Its location was commonly used to help search for vitreous traction using the Line group program. However, for example, if a traction point at the PMB was in proximity to the $\mathrm{ONH}$, and the vitreous strand was directed vertically (Figure 1), no signal of a vitreous strand would be apparent in any of the six radial scans, even if the scan passed at the same foveal-PMB axis, as it did not reach that point. Only another scan program, such as the manually controlled Line group (or maybe the Automatic Raster line program) could detect that point of adherence and traction.

The centrally fixated Automatic 6-radial lines program omitted $16 \%$ (4 of the 25 ) of eyes with vitreous traction at the central macula. This may be explained by the fact that the OCT-2 examination starts by manually focusing the OCT on the macula, and the Automatic 6-radial lines program is then initiated. Owing to the initial focus on the macula, in order to detect macular abnormalities and measurements, it is possible that thin vitreous strands, even if adhered to the oedematous macula, may be sometimes vaguely observed or not at all. In relevance, $\mathrm{Hee}^{22}$ noted that maladjustment of the OCT focus might result in a 'degraded image' and artifacts. The repeated change of focus using the Line group OCT-2 program, directing it towards the vitreomacular interface or the posterior vitreous, as well as between the standard $30^{\circ}$ of arc of the Automatic program, could explain the reason why the Line group program could confirm wavering vitreous traction at the fovea in only $16 \%$ of cases.

As a whole, the Automatic 6-radial lines program detected vitreous traction sites in only $58 \%(n=26)$ of the 45 eyes. Therefore, this program was not sufficient to provide a confident diagnosis of vitreous tractions at the sites scanned by the OCT in eyes with macular oedema. The Line group OCT-2 program, which is controlled manually, provided the other $42 \%$ confirmatory data, both on vitreofoveal and extrafoveal traction, at the retina or at the ONH.

Except for vitreopapillary traction, ${ }^{16}$ earlier studies on DME without vitreomacular traction did not regularly mention or rule out extrafoveal traction. In that regard, reports on PPV outcome for eyes with macular oedema, without vitreomacular traction, are diverse. Several studies found PPV beneficial in such eyes with diffuse DME. ${ }^{14,20,26}$ Few authors suggested that surgical success could be partly related to removal of growth factors associated with macular oedema from the vitreous site. ${ }^{27}$ In contrast, other studies report that PPV would be beneficial only in eyes with macular oedema associated with vitreomacular traction, but not when macular traction was undetected. ${ }^{20,28}$ However, La Heij et al ${ }^{21}$ found that functional surgical success is significantly better in eyes that had not had previous laser treatment(s) than in eyes that had undergone laser photocoagulation for DME. The authors suggest that in addition to the harmful, sometimes repeated, laser treatment for macular oedema, the associated delay until surgery may partly explain the surgical failure in these studies. Therefore, in eyes with diabetic diffuse macular oedema associated with extrafoveal traction, it would probably be of importance to study whether early PPV, rather than laser treatment or intravitreal administration of medication, could improve surgical outcome.

In four $(20 \%)$ of the 20 eyes in which extrafoveal vitreo-retinal traction sites were detected, no association between the underlying retinal oedema and the central macular oedema could be verified. This finding should be considered if a therapeutic agent is planned intravitreally. Arevalo et $\mathrm{l}^{29}$ report that traction retinal detachment may occur or progress shortly after administration of intravitreal Bevacizumab, in patients with severe proliferative diabetic retinopathy. Honda et $a l^{30}$ report on a premature newborn with retinopathy

of prematurity, in which acute contraction of the proliferative membrane and aggravation of the retinal detachment occurred after intravitreal injection of Bevacizumab.

In the same four eyes with extrafoveal vitreous traction sites, in which we could not verify an association between the adjoining retinal oedema and the central macula, it may be possible that another undetected site of vitreous traction existed. Once a traction membrane was detected, the search for others was usually discontinued. In retrospect, other traction sites had to be searched, at least in these four eyes. In that regard, Gallemore et $a l^{31}$ point out that two distinct vitreoretinal adhesion patterns may be identified with the 2D OCT, each associated with a partial separation of the posterior hyaloid face: focal and multifocal. Further studies will indicate whether the new generation 3D OCT ${ }^{32}$ will detect vitreo-traction sites with higher confidence of accuracy and much faster than the $2 \mathrm{D}$ time-domain OCT.

Limitations of this study refer to its retrospective design, and the possibility that other undetectable vitreo-traction sites associated with DME were apparent. However, such a finding is not expected to change the study conclusions, but rather can even strengthen it. In summary, our study points to the fact that diffuse DME may be associated with extrafoveal vitreous traction. The centrally fixated 6-radial lines OCT program omitted definite detection in $16 \%$ of the vitreofoveal adherence and tractions, and detected only $58 \%$ of the vitreous traction sites overall. The other $42 \%$ of traction sites were detected only by the manually controlled OCT-2 Line group program. Further studies are required to validate the clinical consequence of these findings. 


\section{References}

1 Cunha-Vaz JG. The blood-retinal barriers. Doc Ophthalmol 1976; (15)41: 287-327.

2 Vinores SA, Youssri AI, Luna JD, Chen YS, Bhargave S, Vinores MA et al. Upregulation of vascular endothelial growth factor in ischemic and non-ischemic human and experimental retinal disease. Histol Histopathol 1997; 12: 99-109.

3 Lobo CL, Bernardes RC, de Abreu JR, Cunha-Vaz JG. One-year follow-up of blood-retinal barrier and retinal thickness alterations in patients with type 2 diabetes mellitus and mild nonproliferative retinopathy. Arch Ophthalmol 2001; 199: 1469-1474.

4 Sander B, Larsen M, Moldow B, Lund-Anderden H. Diabetic macular oedema: passive and active transport of fluorescein through the blood-retina barrier. Invest Ophthalmol Vis Sci 2001; 42: 433-438.

5 Oauml T, Xu O, Joussen AM, Clemens MW, Qin W, Miyamoto $\mathrm{K}$ et al. VEGF-initiated blood-retinal barrier breakdown in early diabetes. Invest Ophthalmol Vis Sci 2001; 42: 2408-2413

6 Early Treatment Diabetic Retinopathy Study Research Group. Early Treatment Diabetic Retinopathy Study report no 1: photocoagulation for diabetic macular oedema. Arch Ophthalmol 1985; 103: 1796-1806.

7 Lee CM, Olk RJ. Modified grid laser photocoagulation for diffuse diabetic macular oedema: long term visual results. Ophthalmology 1991; 98: 1594-1602.

8 Jonas JB, Kreissig I, Sofker A, Degenring RF. Intravitreal injection of triamcinolone for diffuse diabetic macular oedema. Arch Ophthalmol 2003; 121: 57-61.

9 Ohguro N, Okada AA, Tano Y. Trans-Tenon's retrobulbar traimcinolone infusion for diffuse diabetic macular oedema. Graefe's Arch Clin Exp Ophthalmol 2004; 242: 444-445.

10 Shinura M, Nakazawa T, Yasuda K, Shiono T, Iida T, Sakamoto $\mathrm{T}$ et al. Comparative therapy evaluation of intravitreal bevacizumab and triamcinolone acetonide on persistent diffuse diabetic macular oedema. Am J Ophthalmol 2008; 145: 854-861.

11 Haritoglou C, Kook D, Neubauer A, Wolf A, Priglinger S, Strauss $\mathrm{R}$ et al. Intravitreal bevacizumab (Avastin) therapy for persistent diffuse diabetic macular oedema. Retina 2006; 26: 999-1005.

12 Wu L, Martinez-Castellanos MA, Quiroz-Mercado H, Arevalo JF, Berrocal MH, Farah ME et al. for the Pan American Collaborative Retina Group (PACORES). Twelve-month safety of intravitreal injections of bevacizumab (Avastin ${ }^{\mathrm{R}}$ ): results of the Pan-American Collaborative Retina Study Group (PACORES). Graefes Arch Clin Exp Ophthalmol 2008; 246: 81-87.

13 Kaiser PK, Riemann CD, Sears JE, Lewis H. Macular traction detachment and diabetic macular oedema associated with posterior hyaloidal traction. Am J Ophthalmol 2001; 131: 44-49.

14 Dillinger P, Mester U. Vitrectomy with removal of the internal limiting membrane in chronic diabetic macular oedema. Graefe's Arch Clin Exp Ophthalmol 2004; 242: 630-637.

15 Shah SP, Patel M, Thomas D, Aldington S, Laidlaw DA. Factors predicting outcome of vitrectomy for diabetic macular oedema: results of a prospective study. Br J Ophthalmol 2006; 90: 33-36.
16 Karatas M, Ramirez JA, Ophir A. Diabetic vitreopapillary traction and macular oedema. Eye 2005; 19: 676-682.

17 Lewis H, Abrams GW, Blumenkrnaz MS, Campo RV. Vitrectomy for diabetic macular traction and oedema associated with posterior hyaloidal traction. Ophthalmology 1992; 99: 753-759.

18 Massin P, Duguid G, Erginay A, Haouchine B, Gaudric A. Optical coherence tomography for evaluating diabetic macular oedema before and after vitrectomy. Am J Ophthalmol 2003; 135: 169-177.

19 Song SJ, Sohn JH, Park KH. Evaluation of the efficacy of vitrectomy for persistent diabetic macular oedema and associated factors predicting outcome. Korean J Ophthalmol 2007; 21: 146-150.

20 Figueroa MS, Contreras I, Noval S. Surgical and anatomical outcomes of pars plana vitrectomy for diffuse nontractional diabetic macular oedema. Retina 2008; 28: 420-426.

21 La Heij EC, Hendrikse F, Kessels AG, Derhaag PJ. Vitrectomy results in diabetic macular oedema without evident vitreomacular traction. Graefe's Arch Clin Exp Ophthalmol 2001; 239: 264-270.

22 Hee MR. Artifacts in optical coherence tomography topographic maps. Am J Ophthalmol 2005; 139: 154-155.

23 Goebel W, Kretzchmar-Gross T. Retinal thickness in diabetic retinopathy: a study using optical coherence tomography (OCT). Retina 2002; 22: 759-767.

24 Massin P, Vicaut E, Haouchine B, Erginay A, Paques M, Gaudric A. Reproducibility of retinal mapping using optical coherence tomography. Arch. Ophthalmol. 2001; 119: 1135-1142.

25 Ramirez JA, Ophir A. Inner lamellar macular holes vs. macular pseudoholes with normal foveal thickness. Int J Ophthalmol (China) 2003; 3: 4-8.

26 Yanayali A, Horozoglu F, Celik E, Nohutcu AF. Long-term outcomes of pars plana vitrectomy with internal limiting membrane removal in diabetic macular oedema. Retina 2007; 27: 557-566.

27 Nguyen QD, Tatlipinar S, Shah SM, Haller JA, Quinlan E, Sung $\mathrm{J}$ et al. Vascular endothelial growth factor is a critical stimulus for diabetic macular oedema. Am J Ophthalmol 2006; 142: 961-969.

28 Patel JI, Hykin PG, Schadt M, Loung V, Bunce C, Fitzke F et al. Diabetic macular oedema: pilot randomised trial of pars plana vitrectomy vs. macular argon photocoagulation. Eye 2006; 20: 873-881.

29 Arevalo JF, Maia M, Flynn Jr HW, Saravia M, Avery RL, Wu $\mathrm{L}$ et al. Tractional retinal detachment following intravitreal bevacizumab (Avastin) in patients with severe proliferative diabetic retinopathy. Br J Ophthalmol 2008; 92: 213-216.

30 Honda S, Hirabayashi H, Tsukahara Y, Negi A. Acute contraction of the proliferative membrane after an intravitreal injection of bevacizumab for advanced retinopathy of prematurity. Graefes Arch Clin Exp Ophthalmol 2008; 246: 1061-1063.

31 Gallemore RP, Jumper JM, McCuen BW, Jaffe GJ, Postel EA, Toth CA. Diagnosis of vitreoretinal adhesions in macular disease with optical coherence tomography. Retina 2000; 20: 115-120.

32 Nassif N, Cense B, Park BH, Yun SH, Chen TC, Bouma BE et al. In vivo human retinal imaging by ultrahigh-speed spectral domain optical coherence tomography. Opt Lett 2004; 29: 480-482.

Supplementary Information accompanies the paper on Eye website (http://www.nature.com/eye) 